\title{
Functional Inactivation of the Amygdala before But Not after Auditory Fear Conditioning Prevents Memory Formation
}

\author{
Ann E. Wilensky, Glenn E. Schafe, and Joseph E. LeDoux \\ W. M. Keck Foundation Laboratory of Neurobiology, Center for Neural Science, New York University, \\ New York, New York 10003
}

Two competing theories predict different effects on memory consolidation when the amygdala is inactivated after fear conditioning. One theory, based on studies using inhibitory avoidance training, proposes that the amygdala modulates the strength of fear learning, and post-training amygdala manipulations interfere with memory consolidation. The other, based on studies using Pavlovian fear conditioning, hypothesizes that fear learning occurs in the amygdala, and post-training manipulations after acquisition will not affect memory consolidation. We infused the $\mathrm{GABA}_{\mathrm{A}}$ agonist muscimol $(4.4 \mathrm{nmol} / \mathrm{side})$ or vehicle into lateral and basal amygdala (LBA) of rats either

Considerable evidence has implicated the amygdala in Pavlovian fear conditioning, in which a neutral conditioned stimulus (CS), such as a tone, acquires the capacity to elicit defensive responses after association with a noxious unconditioned stimulus (US), such as foot shock. Lesion, tract-tracing, and electrophysiological studies collectively suggest that fear conditioning involves the transmission of sensory information about the CS and US to the lateral nucleus of the amygdala (LA), which is thought to encode key aspects of the learning. The LA then transfers the information to the central nucleus of the amygdala (CE), where output projections to brainstem areas control the expression of conditioned fear responses (Davis, 1994; LeDoux, 1996; Maren and Fanselow, 1996). The involvement of the amygdala in fear conditioning is also supported by recent functional MRI and lesion studies in humans (Bechara et al., 1995; LaBar et al., 1995, 1998; Morris et al., 1998).

A recent study in our laboratory used the $\mathrm{GABA}_{\mathrm{A}}$ agonist muscimol to functionally inactivate the amygdala before training (Muller et al., 1997). When tested drug-free the next day, rats displayed little conditioned fear to contextual or auditory conditioned stimuli. Although these findings suggested that neural activity is required in the amygdala during Pavlovian conditioning, there is, however, a second possible interpretation. A number of studies have shown that manipulations of the amygdala immediately after training can modulate memory for instrumental learning tasks (Cahill and McGaugh, 1998; Packard and Teather,

\footnotetext{
Received Aug. 26, 1999; revised Oct. 18, 1999; accepted Oct. 18, 1999.

This research was supported in part by National Institute of Mental Health Grants RO1 MH46516, KO2 MH00956, and R37 MH38774. The work was also supported by a grant from the W. M. Keck Foundation to New York University. We thank Nicole Nadel for technical assistance. We also thank Karim Nader for helpful comments about this manuscript.

Correspondence should be addressed to Dr. Joseph E. LeDoux, Center for Neural Science, New York University, 4 Washington Place, Room 809, New York, NY 10003. E-mail: ledoux@cns.nyu.edu.

Copyright (C) 1999 Society for Neuroscience $\quad 0270-6474 / 99 / 190001-\bullet \$ 05.00 / 0$
}

before or immediately after tone-foot shock Pavlovian fear conditioning. Pre-training infusions eliminated acquisition, whereas post-training infusions had no effect. These findings indicate that synaptic activity in LBA is necessary during learning, but that amygdala inactivation directly after training does not affect memory consolidation. Results suggest that essential aspects of plasticity underlying auditory fear conditioning take place within LBA during learning.

Key words: muscimol; learning; memory consolidation; amygdala; auditory fear conditioning; GABA
1998). In particular, immediate post-training, intra-amygdala manipulations of the GABAergic system affect inhibitory avoidance learning (Brioni et al., 1989; Castellano et al., 1989; Izquierdo et al., 1990, 1997; Dickinson-Anson and McGaugh, 1997). These results have been used to propose that the acquisition and consolidation of fear memory occur outside of the amygdala, and that the role of the amygdala is to modulate memory consolidation in other areas. If correct, the results reported by Muller et al. (1997) on conditioned fear may be interpreted as a post-training effect on memory consolidation in other brain regions, because of lingering effects of the drug in the amygdala. This is a particularly important issue in light of recent evidence suggesting that the strength of Pavlovian contextual fear conditioning can be modulated by post-training drug infusion into the amygdala (Vazdarjanova and McGaugh, 1999).

The present experiment was designed to determine whether the previously documented effects of pre-training muscimol on auditory fear conditioning are attributable to the inactivation of the amygdala during training or to post-training modulation by the amygdala on memory consolidation in other brain areas. To test this, we infused muscimol into the amygdala either before or immediately after auditory fear conditioning. If the amygdala modulates the consolidation of fear memory in other brain re-

This article is published in The Journal of Neuroscience, Rapid Communications Section, which publishes brief, peerreviewed papers online, not in print. Rapid Communications are posted online approximately one month earlier than they would appear if printed. They are listed in the Table of Contents of the next open issue of JNeurosci. Cite this article as: JNeurosci, 1999, 19:RC48 (1-5). The publication date is the date of posting online at www.jneurosci.org.

http://www.jneurosci.org/cgi/content/full/3790 
gions, we would expect to find effects after both pre- and posttraining injections. In contrast, if functional inactivation of the amygdala immediately after training fails to affect memory consolidation of fear conditioning, the results would favor the view that essential aspects of the memory underlying conditioned fear are acquired in the amygdala.

\section{MATERIALS AND METHODS}

Subjects. Twenty-two naive male Sprague Dawley rats (Hilltop Labs, Scottdale, PA), weighing 250-300 gm, were housed in pairs in plastic Nalgene cages and placed on a $12 \mathrm{hr}$ light/dark cycle with ad libitum food and water. All procedures were in accordance with the National Institutes of Health guide and were approved by the New York University Animal Care and Use Committee.

Surgery. Rats were anesthetized with Nembutal $(40 \mathrm{mg} / \mathrm{kg}$, i.p.) and treated with atropine sulfate $(0.4 \mathrm{mg} / \mathrm{kg})$. Using a stereotaxic frame, guide cannulae (22 gauge; Plastics One, Roanoke, VA) fitted with internal cannulae that extended out by $1.5 \mathrm{~mm}$ were positioned just above the lateral and basal amygdala (LBA) using coordinates taken from Paxinos and Watson (1986) (2.8 mm posterior to bregma, $8.0 \mathrm{~mm}$ ventral to skull surface, and $5.3 \mathrm{~mm}$ lateral to midline). The guide cannulae were fixed to screws in the skull using cranioplastic cement (Plastics One). After the cement hardened, internal cannulae were replaced with dummy cannulae, cut $0.5 \mathrm{~mm}$ longer than the guides, to prevent clogging. Rats were tested the following week after full recovery.

Intracranial injections. Rats were held in the experimenter's lap while dummy cannulae were replaced with 28 -gauge injector cannulae attached to $1.0 \mu \mathrm{l}$ Hamilton syringes via polyurethane tubing. The tubing was back-filled with sesame oil, and a small air bubble separated the oil from the drug solution. Drugs were infused bilaterally by an infusion pump at a rate of $0.25 \mu \mathrm{l} / \mathrm{min}$. After drug infusion, cannulae were left in place for an additional 1 min to allow diff usion of the drug away from the cannula tip, after which the dummy cannulae were replaced.

Apparatus. Fear conditioning took place in a Plexiglas rodent conditioning chamber with a metal grid floor (model E10-10; Coulbourn Instruments, Lehigh Valley, PA), dimly illuminated by a single house light and enclosed within a sound-attenuating chamber (model E10-20). Testing for conditioned fear responses occurred in a brightly lit Plexiglas chamber with three house lights (ENV-001; MedAssociates, Inc., Georgia, VT), fitted with a flat black Formica floor that had been washed with a peppermint-scented soap. Previous studies have shown that this distinct testing environment minimizes generalization from the training environment (Schafe et al., 1999; Nader and LeDoux, 1999). A video camera mounted at the top of the chamber recorded behavior for later scoring.

Habituation, conditioning, and testing. Figure $1 A$ outlines the general experimental procedures for rats injected before training, and Figure $2 A$ outlines the general experimental procedures for rats injected after training. On day 1 , rats were habituated to the training and testing chambers for a minimum of $10-15$ min, as well as to handling and dummy cannula removal and replacement. To control for possible order effects, habituation was counterbalanced between groups.

Conditioning occurred on day 2. Rats were divided into four groups that received either muscimol $(4.4 \mathrm{nmol} /$ side in $0.5 \mu \mathrm{l})$ or saline vehicle $(0.9 \%, 0.5 \mu \mathrm{l})$ before or after training. Pre-training inf usions $(n=5$, both groups) occurred 40-70 min before conditioning. Post-training injections ( $n=6$, both groups) occurred immediately after the final tone-shock pairing, with the drug completely inf used into the amygdala within $5 \mathrm{~min}$ of the last shock. For training, rats were allowed 2-3 min to acclimate to the conditioning chamber and were then presented with five pairings of a $20 \mathrm{sec}$ tone $\mathrm{CS}(5 \mathrm{kHz}, 75 \mathrm{~dB})$ that co-terminated with a foot shock US $(0.5 \mathrm{sec}, 0.5 \mathrm{~mA})$. The intertrial interval varied randomly between 90 and $120 \mathrm{sec}$. After conditioning and drug infusion, rats were returned to their home cages and to the colony.

Testing took place $\sim 24 \mathrm{hr}$ after conditioning. Rats were videotaped during testing for later scoring. After a 3-5 min acclimation period to the test chamber, rats were presented with three $30 \mathrm{sec}$ tones $(5 \mathrm{kHz}, 75 \mathrm{~dB}$; intertrial interval, $100 \mathrm{sec}$ ). A $30 \mathrm{sec}$ tone was used to maximize observation of potential differences between groups. After tone testing, rats were returned to their home cages and to the colony.

Fear memory was evaluated from the videotape by measuring the number of seconds during each tone presentation where rats engaged in freezing behavior, defined as a lack of all movement with the exception of respiration. Data were analyzed with ANOVA and Scheffe's post hoc $t$ tests.
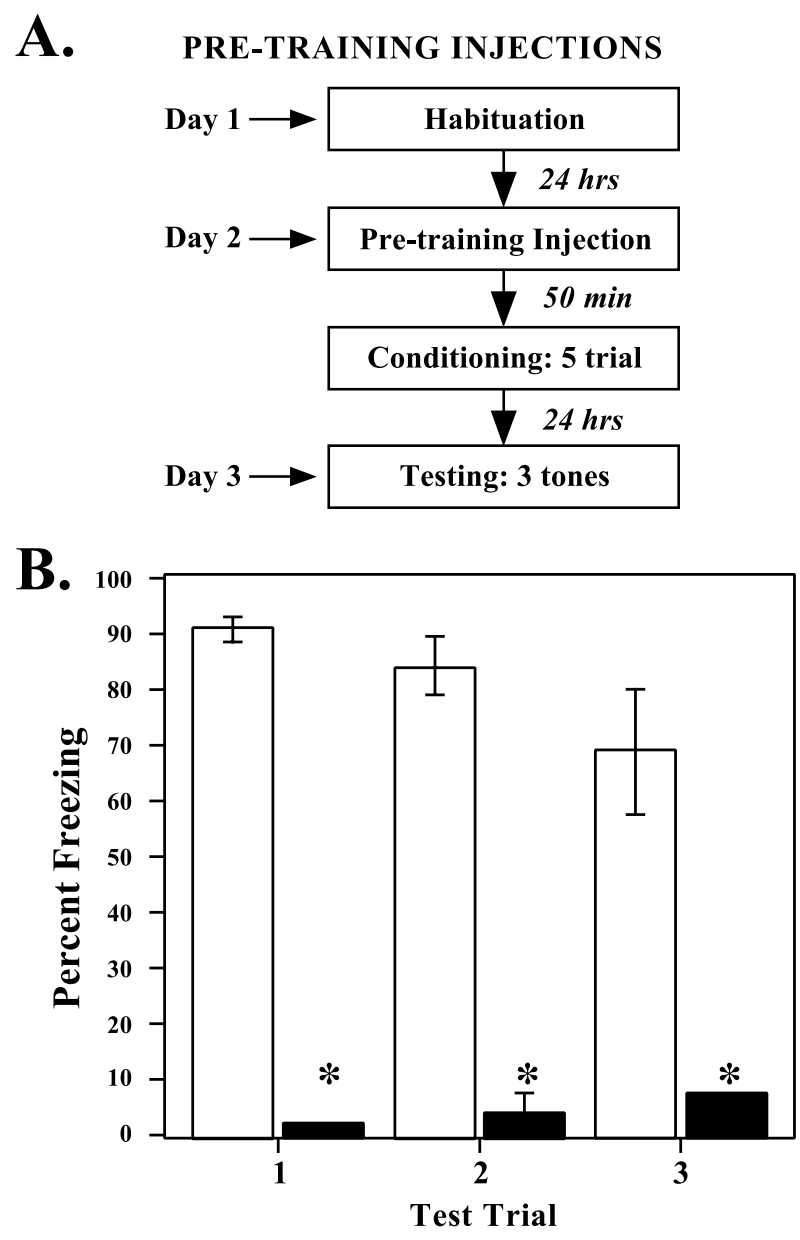

Figure 1. Pre-training injections. $A$, Outline of general behavioral procedures and timing for pre-training injections. $B$, Mean \pm SE percent freezing for each test trial in rats receiving pre-training injections of saline (white bars) or muscimol (black bars). ${ }^{*} p<0.01$ relative to saline-injected controls.

Histology. To verify injector tip location, rats were anesthetized with an overdose of Nembutal $(100 \mathrm{mg} / \mathrm{kg}$, i.p.) and perfused transcardially with $0.9 \% \mathrm{NaCl}$ followed by $10 \%$ buffered Formalin. Brains were postfixed in $30 \%$ sucrose in $10 \%$ buffered Formalin and subsequently blocked, sectioned on a cryostat at $50 \mu \mathrm{m}$, and stained for Nissl using either $0.5 \%$ cresyl violet or $0.25 \%$ thionine. Sections were coverslipped with Permount and examined under light microscopy for injector tip penetration into the amygdala.

\section{RESULTS}

\section{Pre-training injections}

Figure $1 B$ shows the mean \pm SE percent freezing during the three test tone presentations for rats injected before conditioning. The group-by-trial, repeated measures (trial) ANOVA showed a significant effect for group $\left(F_{(1,8)}=189.68 ; p<0.001\right)$, a significant group-by-trial interaction $\left(F_{(12,16)}=5.01 ; p<0.05\right)$, and no significant effect of trial $\left(F_{(2,16)}=1.90\right)$. Individual post hoc $t$ tests showed a significant difference between the saline and muscimol groups for each of the three test trials $(p<0.001)$. Consistent with previous findings (Muller et al., 1997), pre-training injections of muscimol prevented the acquisition of fear to the CS; the rats displayed very little freezing during the tone presentations relative to saline-injected controls. 
A. POST-TRAINING INJECTIONS

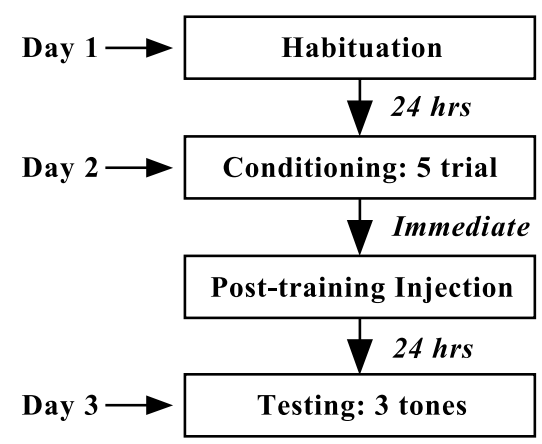

B.

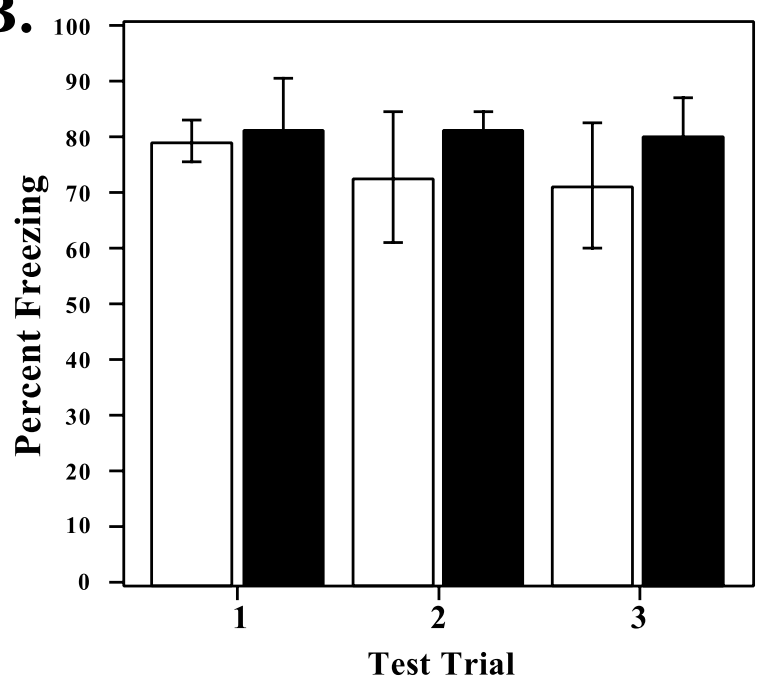

Figure 2. Post-training injections. $A$, Outline of general behavioral procedures and timing for post-training injections. $B$, Mean \pm SE percent freezing for each test trial in rats receiving post-training injections of saline (white bars) or muscimol (black bars).

\section{Post-training injections}

Although pre-training infusions of muscimol blocked fear acquisition, post-training infusions had no significant effects for group $\left(F_{(1,10)}=0.39\right)$, trial $\left(F_{(2,20)}=0.34\right)$, or group-by-trial interaction $\left(F_{(2,20)}=0.32\right.$; Figure $\left.2 B\right)$. Rats injected with muscimol showed the same high percentage of freezing behavior during tone presentations as rats injected with saline. Thus, in contrast to the inhibitory avoidance studies in which post-training infusions appear to affect consolidation (Brioni et al., 1989; Izquierdo et al., 1990, 1997; Dickinson-Anson and McGaugh, 1997), inactivation of the amygdala by muscimol immediately after training had no effect on the retention of auditory fear conditioning.

\section{Histology}

Figure 3 shows the injector tip locations for all rats. Injector tips were mostly located in the lateral amygdala, with a few just outside LA, or in the basal and central nuclei. Because the behavioral results were not systematically related to the cannula locations, all animals were included in the analysis.

\section{DISCUSSION}

Research focusing on the role of amygdala in aversive learning has produced two competing theories regarding its role in conditioned fear. One theory, based on investigations of Pavlovian fear

\section{bregma}
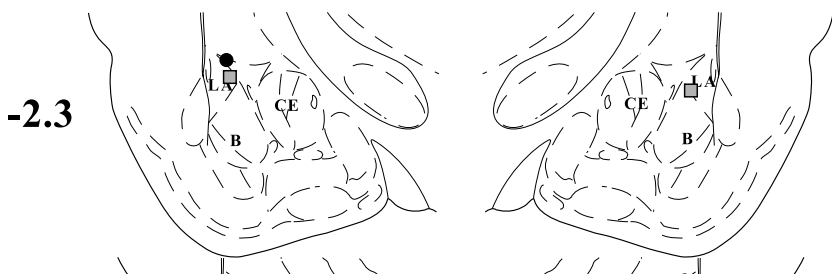

$-2.8$
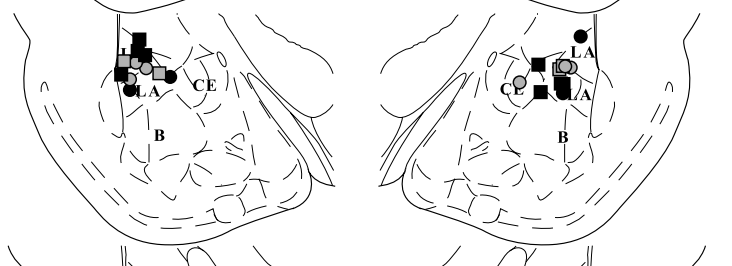

$-3.3$
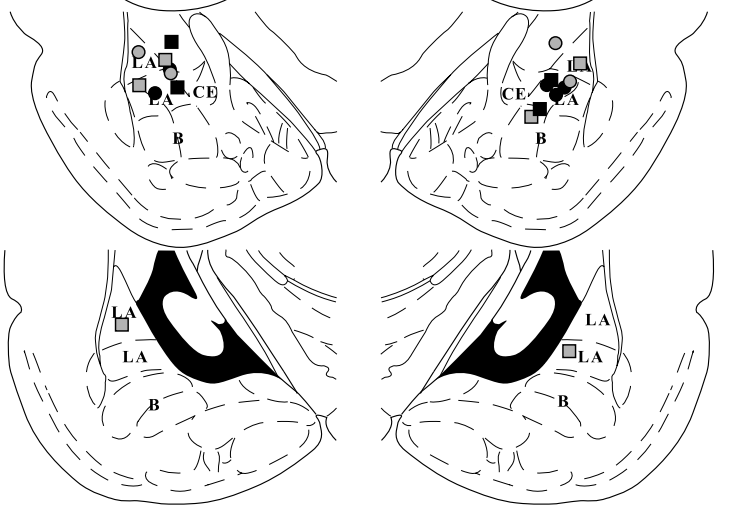

0 nmol muscimol -Pretraining

0 nmol muscimol -Posttraining

4.4 nmol muscimol -Pretraining

4.4 nmol muscimol -Posttraining

Figure 3. Histology: location of cannula tip placements for all animals. Left numbers refer to millimeters posterior to bregma. $L A$, Lateral nucleus; $B$, basal nucleus; $C E$, central nucleus. Figure adapted from Paxinos and Watson (1997).

conditioning, proposes that the amygdala is the site of the plastic changes underlying conditioned fear acquisition, whereas the other hypothesizes that the amygdala plays only a modulatory role in aversive learning. In support of this latter hypothesis, a number of studies have reported impaired memory for inhibitory avoidance learning after post-training infusions of muscimol into the amygdala (Brioni et al., 1989; Izquierdo et al., 1990, 1997). These results suggest that GABAergic mechanisms in the amygdala after training can modulate the strength of memory consolidation in other brain areas. Contrary to this hypothesis, however, we found that although pre-training injections of muscimol blocked auditory Pavlovian fear conditioning, immediate posttraining injections had no effect. These results are consistent with those of previous studies, including work using intra-amygdala administration of AP5, in which AP5 impaired Pavlovian fear conditioning if given before, but not if given immediately after, training (Helmstetter and Bellgowan, 1994; Maren et al., 1996b; Muller et al., 1997). Thus, unlike results obtained using inhibitory avoidance procedures, post-training neural activity in the amygdala does not appear to affect memory consolidation of Pavlovian fear conditioning. In contrast, our findings suggest that essential aspects of the plasticity underlying Pavlovian fear memory occur within the LBA.

One of the key differences between this study and other studies examining post-training manipulations of the amygdala on fear 
learning lies in the type of conditioning used to train the rats. In our Pavlovian experiments, the animal is presented with tones (CS) and shocks (US) independent of its behavior. However, inhibitory avoidance learning is an example of instrumental learning in which, in addition to differences in the nature of the CS and in the demand for distinguishing different components of the apparatus, shock delivery is contingent on the animal's response. Thus, the ability of the amygdala to modulate one type of learning after training and not the other may be a reflection of the relative complexity of the neural network underlying the two types of learning. In fact, although lesion studies have consistently implicated the amygdala in Pavlovian fear conditioning (LeDoux et al., 1990; Maren et al., 1996a; Maren, 1998), lesions of the amygdala appear to have less clear-cut effects on inhibitory avoidance learning (Liang et al., 1982; Parent et al., 1995). Furthermore, pharmacological and lesion studies have implicated the hippocampal formation in early memory phases and entorhinal cortex and parietal cortex in late memory phases of inhibitory avoidance learning (Izquierdo and Medina, 1993; Izquierdo et al., 1997; Zanatta et al., 1997). In contrast, auditory fear conditioning is spared after hippocampal (Anagnostaras et al., 1999) and entorhinal cortex lesions (Phillips and LeDoux, 1995), and parietal lesions affect spatial navigation but not amygdala-dependent Pavlovian tasks such as conditioned taste aversion (Kesner et al., 1992).

The question of whether the effects of post-training manipulation of the amygdala in the inhibitory avoidance conditioning paradigm can also generalize to Pavlovian fear-conditioning tasks was recently addressed by Vazdarjanova and McGaugh (1999). In that study, rats were given multiple-trial Pavlovian contextual fear conditioning, in a closed arm of a Y maze, followed by immediate post-training injections of lidocaine or vehicle. Subsequently, lidocaine-treated rats spent less time engaging in freezing behavior and were more likely to enter the arm of the maze in which they had received shock. Unlike our results obtained with auditory fear conditioning, the results of Vazdarjanova and McGaugh (1999) suggest that memory consolidation of contextual fear conditioning, as well as inhibitory avoidance learning, can be modulated by post-training manipulations of amygdala. This raises the interesting possibility that contextual and auditory fear conditioning can be differentially modulated within the amygdala. Ideally, experiments examining the impact of post-training manipulations of amygdala on both contextual and auditory fear conditioning in the same animals could be used to test this hypothesis. We are currently evaluating this possibility in our laboratory.

Although the results from this study suggest that memory consolidation of auditory fear conditioning is spared after post-training functional inactivation of amygdala, a number of issues remain to be addressed. Although the volume and locus of the drug infusion within the amygdala do not appear to affect results in inhibitory avoidance learning and, therefore, are not considered an issue in our study, two issues of particular importance are currently being addressed in our laboratory. The first is the timing of the injections relative to the beginning of training. Much of the inhibitory avoidance literature is based on a one-trial learning task. Although several studies have shown modulation of memory after multiple-trial inhibitory avoidance and other forms of instrumental learning (Roozendaal et al., 1996; Dickinson-Anson and McGaugh, 1997), effective manipulations of the amygdala GABAergic system have a limited time course (Castellano et al., 1989;
Zanatta et al., 1997). In one study, for example, muscimol was effective at modulating memory consolidation of inhibitory avoidance when injected into amygdala immediately but not 30 min after training (Zanatta et al., 1997). Thus, the five-trial paradigm used in the present study may have allowed some memory consolidation to occur during early training trials. The second issue is drug concentration. Although in the present study it was our intention to evaluate the effects of posttraining administration of the dose that had previously been used in our laboratory (4.4 nmol/side; Muller et al., 1997), previous studies have also found modulatory effects on inhibitory avoidance learning with much lower concentrations of muscimol (Brioni et al., 1989, Izquierdo et al., 1990). Additional experiments will be necessary to evaluate whether either of these factors plays a significant role in determining the degree to which memory is modulated after training.

\section{REFERENCES}

Anagnostaras SG, Maren S, Fanselow MS (1999) Temporally graded retrograde amnesia of contextual fear after hippocampal damage in rats: within-subjects examination. J Neurosci 19:1106-1114.

Bechara A, Tranel D, Damasio H, Adolphs R, Rockland C, Damasio AR (1995) Double dissociation of conditioning and declarative knowledge relative to the amygdala and hippocampus in humans. Science 269:1115-1118.

Brioni JD, Nagahara AH, McGaugh JL (1989) Involvement of the amygdala GABAergic system in the modulation of memory storage. Brain Res 487:105-112.

Cahill L, McGaugh JL (1998) Mechanisms of emotional arousal and lasting declarative memory. Trends Neurosci 21:294-299.

Castellano C, Brioni JD, Nagahara AH, McGaugh JL (1989) Posttraining systemic and intra-amygdala administration of the GABA-B agonist baclofen impairs retention. Behav Neural Biol 52:170-179.

Davis M (1994) The role of the amygdala in emotional learning. Int Rev Neurobiol 36:225-266.

Dickinson-Anson H, McGaugh JL (1997) Bicuculline administered into the amygdala after training blocks benzodiazepine-induced amnesia. Brain Res 752:197-202.

Helmstetter FJ, Bellgowan PS (1994) Effects of muscimol applied to the basolateral amygdala on acquisition and expression of contextual fear conditioning in rats. Behav Neurosci 110:1005-1009.

Izquierdo I, Medina JH (1993) Role of the amygdala, hippocampus and entorhinal cortex in memory consolidation and expression. Braz J Med Biol Res 26:573-589.

Izquierdo I, Da Cunha C, Huang CH, Walz R, Wolfman C, Medina JH (1990) Post-training down-regulation of memory consolidation by a GABA-A mechanism in the amygdala modulated by endogenous benzodiazepines. Behav Neural Biol 54:105-109.

Izquierdo I, Quillfeldt JA, Zanatta MS, Quevedo J, Schaeffer E, Schmitz PK, Medina JH (1997) Sequential role of hippocampus and amygdala, entorhinal cortex and parietal cortex in formation and retrieval of memory for inhibitory avoidance in rats. Eur J Neurosci 9:786-793.

Kesner RP, Berman RF, Tardif R (1992) Place and taste aversion learning: role of basal forebrain, parietal cortex, and amygdala. Brain Res Bull 29:345-353.

LaBar KS, LeDoux JE, Spencer DD, Phelps EA (1995) Impaired fear conditioning following unilateral temporal lobectomy in humans. J Neurosci 15:6846-6855.

LaBar KS, Gatenby JC, Gore JC, LeDoux JE, Phelps EA (1998) Human amygdala activation during conditioned fear acquisition and extinction: a mixed-trial fMRI study. Neuron 20:937-945.

LeDoux JE (1996) Emotional networks and motor control: a fearful view. Prog Brain Res 107:437-446.

LeDoux JE, Cicchetti P, Xagoraris A, Romanski LM (1990) The lateral amygdaloid nucleus: sensory interface of the amygdala in fear conditioning. J Neurosci 10:1062-1069.

Liang KC, McGaugh JL, Martinez Jr JL, Jensen RA, Vasquez BJ, Messing RB (1982) Post-training amygdaloid lesions impair retention of an inhibitory avoidance response. Behav Brain Res 4:237-249.

Maren S (1998) Overtraining does not mitigate contextual fear condi- 
tioning deficits produced by neurotoxic lesions of the basolateral amygdala. J Neurosci 18:3088-3097.

Maren S, Fanselow MS (1996) The amygdala and fear conditioning: has the nut been cracked? Neuron 16:237-240.

Maren S, Aharonov G, Fanselow MS (1996a) Retrograde abolition of conditional fear after excitotoxic lesions in the basolateral amygdala of rats: absence of a temporal gradient. Behav Neurosci 110:718-726.

Maren S, Aharonov G, Stote DL, Fanselow MS (1996b) N-Methyl-Daspartate receptors in the basolateral amygdala are required for both acquisition and expression of conditional fear in rats. Behav Neurosci 110:1365-1374.

Morris JS, Ohman A, Dolan RJ (1998) Conscious and unconscious emotional learning in the human amygdala. Nature 393:467-470.

Muller J, Corodimas KP, Fridel Z, LeDoux JE (1997) Functional inactivation of the lateral and basal nuclei of the amygdala by muscimol infusion prevents fear conditioning to an explicit conditioned stimulus and to contextual stimuli. Behav Neurosci 111:683-691.

Nader K, LeDoux J (1999) The dopaminergic modulation of fear: quinpirole impairs the recall of emotional memories in rats. Behav Neurosci 113:152-165.

Packard MG, Teather LA (1998) Amygdala modulation of multiple memory systems: hippocampus and caudate-putamen. Neurobiol Learn Mem 69:163-203.

Parent MB, Quirarte GL, Cahill L, McGaugh JL (1995) Spared reten- tion of inhibitory avoidance learning after posttraining amygdala lesions. Behav Neurosci 109:803-807.

Paxinos G, Watson C (1986) The rat brain in stereotaxic coordinates, Ed 2. San Diego: Academic.

Paxinos G, Watson C (1997) The rat brain in stereotaxic coordinates: computer graphics files, compact Ed 3. San Diego: Academic.

Phillips RG, LeDoux JE (1995) Lesions of the fornix but not the entorhinal or perirhinal cortex interfere with contextual fear conditioning. J Neurosci 15:5308-5315.

Roozendaal B, Carmi O, McGaugh JL (1996) Adrenocortical suppression blocks the memory-enhancing effects of amphetamine and epinephrine. Proc Natl Acad Sci USA 93:1429-1433.

Schafe GE, Nadel NV, Sullivan GM, Harris A, LeDoux JE (1999) Memory consolidation for contextual and auditory fear conditioning is dependent on protein synthesis, PKA, and MAP kinase. Learn Mem 6:97-110.

Vazdarjanova A, McGaugh JL (1999) Basolateral amygdala is involved in modulating consolidation of memory for classical fear conditioning. J Neurosci 19:6615-6622.

Zanatta MS, Quillfeldt JH, Schaeffer E, Schmitz PK, Quevedo J, Medina JH, Izquierdo I (1997) Involvement of the hippocampus, amygdala, entorhinal cortex and posterior parietal cortex in memory consolidation. Braz J Med Biol Res 30:235-240. 